\title{
CAN ELECTIONS ENSURE REPRESENTATIVE AND ACCOUNTABLE GOVERNMENT? THEORETICAL MODELING
}

\section{Abstract}

The article consists of discourse if elections can be the only part of ensuring of democratic order. The author is analyzing the concepts of electoral representation and electoral accountability and comparing their ideal and real embodiments. The main part of the work is theoretic model with which the author is trying to predict the behavior of an incumbent and to make some crucial notes about abilities of elections to ensure representation and accountability. The crucial conclusion is that elections cannot be the only tool to keep the government representative and accountable and should be supplemented by other democratic instruments. Although the evidences are theoretical, the conclusions can be applied practically.

Key words: democracy, elections, accountability, representation, political mandate model. DOI: 10.51180/RPS.2020.15.2.010.

\section{Author}

\section{Kononenko Oleg S.}

Master's student Political Science Faculty Lomonosov Moscow State University (Moscow, Russia)

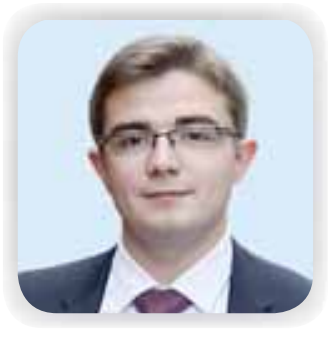

$\mathrm{T}$ here is no more mythologized concept in political science than "democracy". Citizens, politicians, philosophers, and scholars succeeded equally in blurring the concept in the public mind, but nobody had malice - it happened because of idea. Government of the people, by the people, for the people was so attractive that people wanted it to become real as soon as possible without going deeper into details.

Leaving questions about origins and distortions in the concept of democracy and appearance of what is to be said "folk democracy" to political theory, let's concentrate on Schumpeter's definition of democracy as "arrangements for arriving at political decisions which realizes the common good by making the people itself decide issues through the election of individuals who are to assemble in order to carry out is will" [7]. The question is whether elections, and democracy in general, really work as they are considered to do: can people choose the best ones, who would either represent their interests and be the most appropriate people to realize it.

This article is to demonstrate that elections can ensure representation and accountability only with poor probability and to highlight the common mistake of thinking about electoral representation and accountability as taken for granted. In a real (not theoretical) world elected individuals are likely to behave not like electorate wants them to do, and each of us would do the same if held an office, because it happens not because of nature of politicians, but because of system traits. Our main idea is that elections cannot be the only institute to make government representative and accountable, and there must be extra means for this. 
To prove the main thesis of this article consistently, we are to start with key definitions, then show the ideal case of accountable and representative government, after outline some restrictions that usually reduce the chances of creating the ideal world and try to find a solution in order to at least weaken these restrictions.

\section{Elections, Representation and Accountability}

First of all, election is a process in which people vote to choose a person or a group of people to hold an official position. The importance of voting for further discussion should be emphasized in this general definition.

As elections are the central point for us, we assume that vote is an only instrument to make government be representative and accountable.

In its turn, being representative could be understood in two ways: descriptive representation as "standing for a particular group because they share characteristics with the group", such as race, gender, language, religion, or ideology [5]; and active representation as acting "on the best available knowledge; and if individuals are sufficiently well informed so that each of them or average one is more likely than not to reach the correct decision, this knowledge is revealed by the verdict of majority of voters" [4].

We will not stop on descriptive representation as minutely as on active, even though it deserves attention from the perspective of the best electoral system and vote counting method system. On the contrary, it would be useful to go deep into some nuances of active representation. Active representation manifests in two ideal models [2]: the delegate model and the trustee.

The delegate model also has name of the mandate model of representation. According to this concept, there is a strong linkage between what constituents want, what a candidate promises and what he or she is really going to do after winning elections - when the candidate won the mandate. The mandate imposes an obligation to perform as agreed and not to stray even if circumstances got different and preferences of constituents changed.

The trustee model describes a picture of an incumbent that makes his or her political judgements independently, based on his or her perception what would be the best for the voters. This model has deep roots that could be attributed to the English philosopher Edmund Burke, but it is not popular nowadays, because the model weekly correlates with the idea of accountability of elected politicians as it states that in contradistinction to the mandate representation it is harder to judge whether an incumbent perform well or not leaning on neither an agreed plan of action nor agreed outcomes (because there cannot be both any plan and agreed outcomes insofar as voters are to rely completely on their candidates in all political issues).

Accountability, as it was defined by Boven, is a relationship between an actor and a forum, in which the actor has an obligation to explain and to justify his or her conduct, the forum can pose questions and pass judgement, and the actor may face consequences [3]. In our case a forum is constituency and an actor is an incumbent.

In particular, in the traditional theory of democracy accountability means voting for the best candidates and punishing the worst. The problem is that for both of these actions constituents have only one tool - their vote (in a purely elections-focused model). This fact specifies electoral accountability. Governments are 'accountable' if citizens can discern representative from unrepresentative governments and can sanction them appropriately, retaining in office those incumbents who perform well and ousting from office those who do not. It also known as retrospective accountability - their vote as a tool to both punish and reward incumbents, and deci- 
Table 1
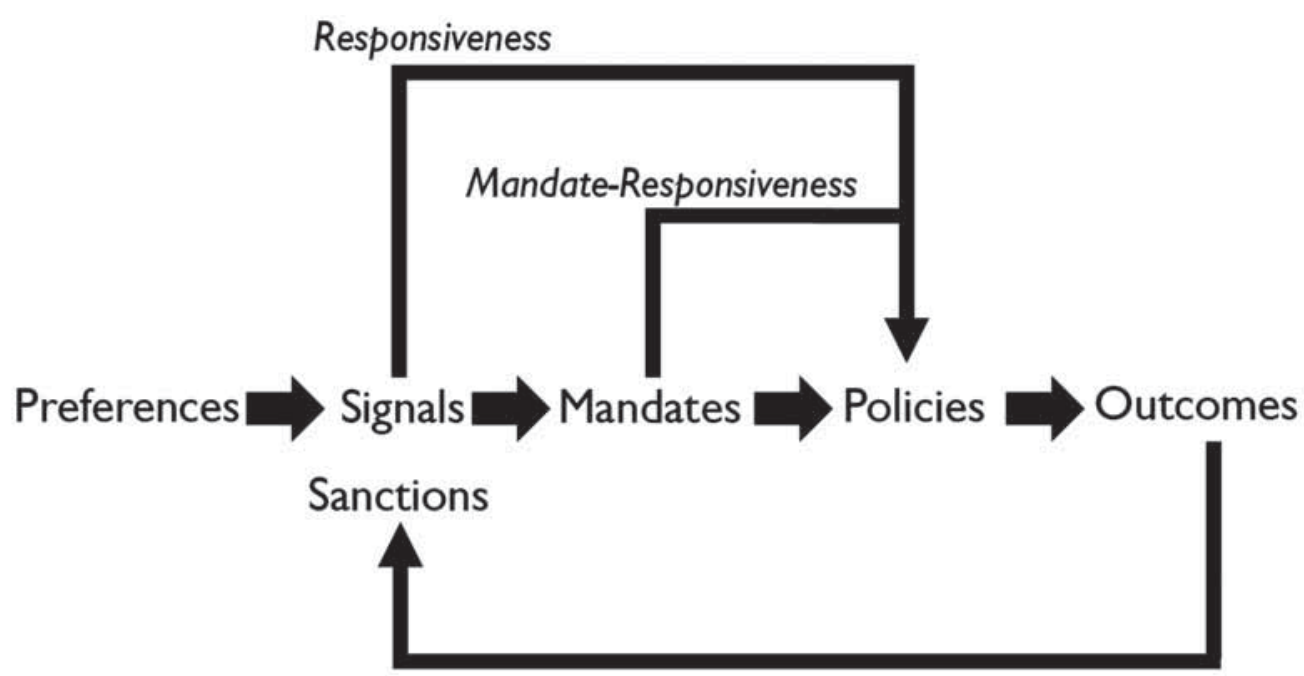

Accountability

sions of whether to choose between them is based on the results of the policy [6].

With a view to simplify and make these concepts more applicable for our case, say that electoral representation means acting in the best interests of the public and according to the mandate, while electoral accountability means capability to choose the best politicians who fits the office, sanction bad politicians by ousting from the office and reward politicians if they performed well by retaining in the office. Przeworski, Stokes, and Manin summarize all these potential relationships in a diagram (Table 1):

\section{How it should be}

An ideal electoral democracy suggests that there is a fully representative and accountable government with governors that perform in concordance with their campaign promises (the mandate). If they are successful, people reward them by reelecting and allowing to continue their policy. If they are unsuccessful or dishonest (cheating on policy, shirking, or pursuing personal profit), people punish them by not reelecting for the next term.

Before these ideal representation and accountability might have happened, we need to stipulate some assumptions: a) voters believe that politicians are not the same and they are given real atternatives;

b) voters are well-informed about candidates and their programs;

c) voters have their own real attitudes towards issues;

d) voters track what is happening with policy after elections and decide to punish or reward;

e) voters clearly understand who is responsible for this or that policy.

We need to recognize that some actions of politicians contribute more to representative and accountable government than another: hold an office when your views coincide with views of voters is better than hold it because of the desire to hold an office or use it in own private interests; providing policy as it was agreed in mandate is better than change your mind about the process (even if a new way is more profitable); not seeking for reelection is more respectful than declaring openly your desire to stay in the office; staying principled is better than changing your views; staying responsible and wellperforming for the last term as well as for the previous ones is better than becoming less efficient in the last term.

If all conditions are met, in the best (ideal) world a politician would hold an 
office because he or she is interested in pursuing a policy which shares common views with voters, and implementing the policy well and efficiently, because it is clear that he or she is being tracked by informed voters, has no desire of reelection just for reelection, is interested in results of policy because wants it to be successfully implemented for him- or herself and not seeking reelection. It is the democracy of full representation and full accountability.

\section{How it really is}

In real world our assumptions fail and make the whole model fail as well. It was described in detail in Achen and Bartels's "Democracy for Realists" [1]. In a great empirical material they emphasized that voters are rarely well-informed about policy, don't have their own stable attitudes to political problems and don't punish or reward candidates for their performance. They turned to be biased to the party or certain candidate (not to make decisions based on own preferences); to not respond the policy for the whole term, but only for the recent times; to vote for the candidate because of sunny weather or their favorite football team good performance. And politicians turned to be not as noble as it is in ideal. They have their own interests which may prevail. Moreover, incentives to perform well and fair are weaker than incentives to gain personal goals.

If we consider incumbents as rational individuals, it becomes clear why they don't perform as political theorists and philosophers expect them to do. They have a space of opportunity in which each action has its own costs and benefits. As a rational individual, an incumbent is interested in maximizing profits. Particular profit depends of an incumbent's real objectives and preferences.

We can distinguish three objectives for every politician to take an office: their policy goals (when a person goes into politics to realize policy he or she wants to be realized), hold an office (when a person just wants to become an authority), and private gains (when a person needs an official position to raise his or her welfare or use influence for business or corruption). Each of these objectives involves three types of actions that range from the least

Table 2

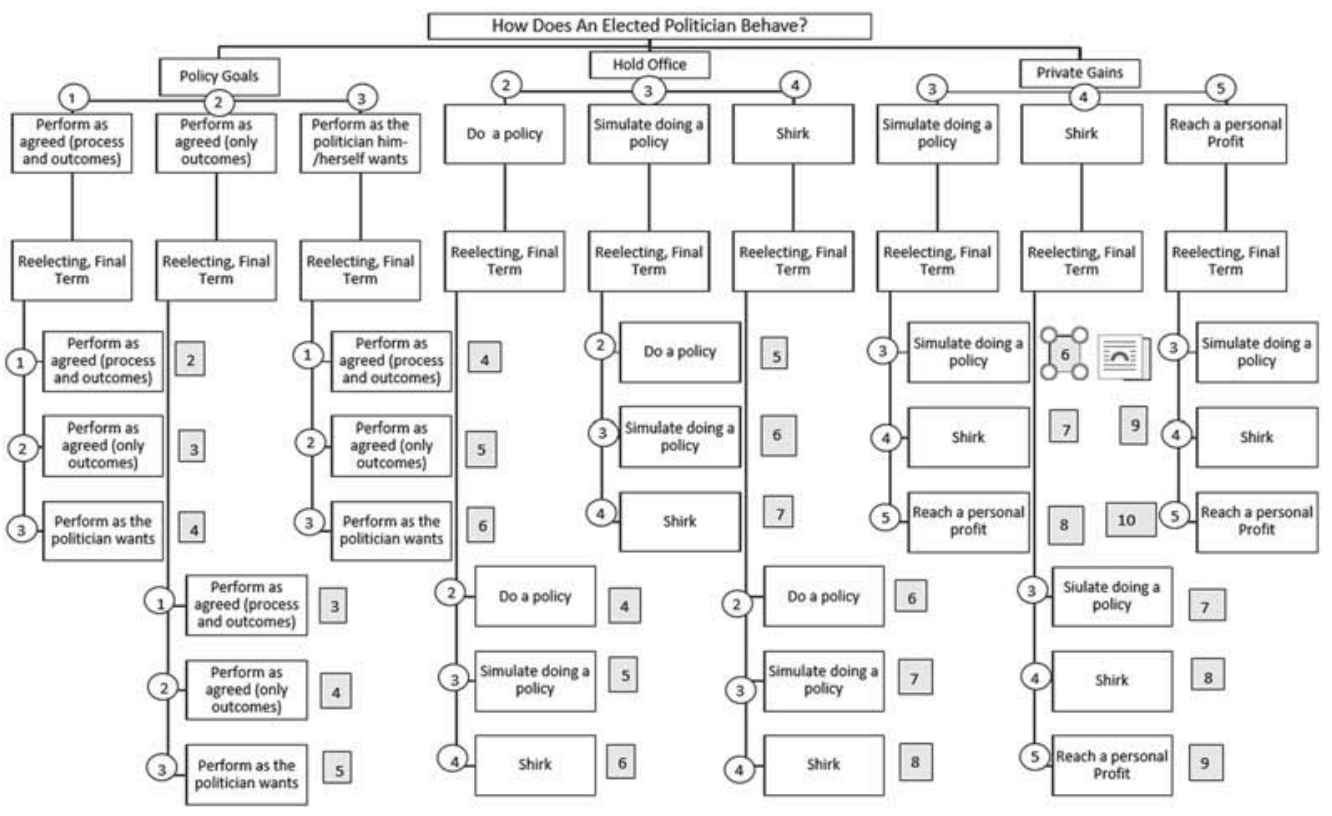


beneficial to the most beneficial for the incumbent.

Let's visualize how can an incumbent behave according to their own interests based on best practices of Achen and Bartels and Przeworski, Stokes and Manin (Table 2). This scheme is to simplify and systematize incumbents' behavior.

For clarity we marked incumbents' benefits with points - "rents" (the numbers in circles in the table). We assume that taking an office to realize the particular policy, performing only as agreed (in process and outcomes) without independence and getting only salary (without extra benefits such as prizes, privileges, bribes, etc.) is, of course, an exemplary way to perform, but the least beneficial for a rational incumbent, therefore the rent for this strategy is 1 . The next strategy - to perform as agreed only in outcomes - imposes less costs for an incumbent, because he or she can change the mind about appropriate ways and be freer in this question, that's why the rent is bigger -2 .

In case an incumbent is motivated by just holding an office, strategies will be different. The least beneficial for him or her would be if an incumbent just do his or her job. At the same time, it is anyway more beneficial than the first case of performing as agreed in process and out- comes, because the incumbent already enjoy his or her office, but less beneficial than simulating activities or shirking and just enjoying themselves.

There is the same logic if an incumbent holds an office for his or her personal goals. The incumbent is not interested in qualitative political performance, but he or she still need at least simulate doing something expected by the others, but it would be more beneficial for him or her just to go about personal business.

At the same moment, an incumbent worries about reelection too, that's why we allocated separately the part that contains reelecting. It has the special meaning in case of reelecting for the final term (if there are any limits about reelecting, such as limits for being a president no more than two consecutive terms in many of countries), because after the final term nobody can punish the incumbent by notreelecting, so as his or her time is anyway over. We believe that the behavior of incumbents during the final term especially tends to be more benefits-focused, because during their last term they are less accountable than ever.

So rents are small when an incumbent gets only a salary for his job and does what he or she supposed to do [6]. When an incumbent gets some extra value from

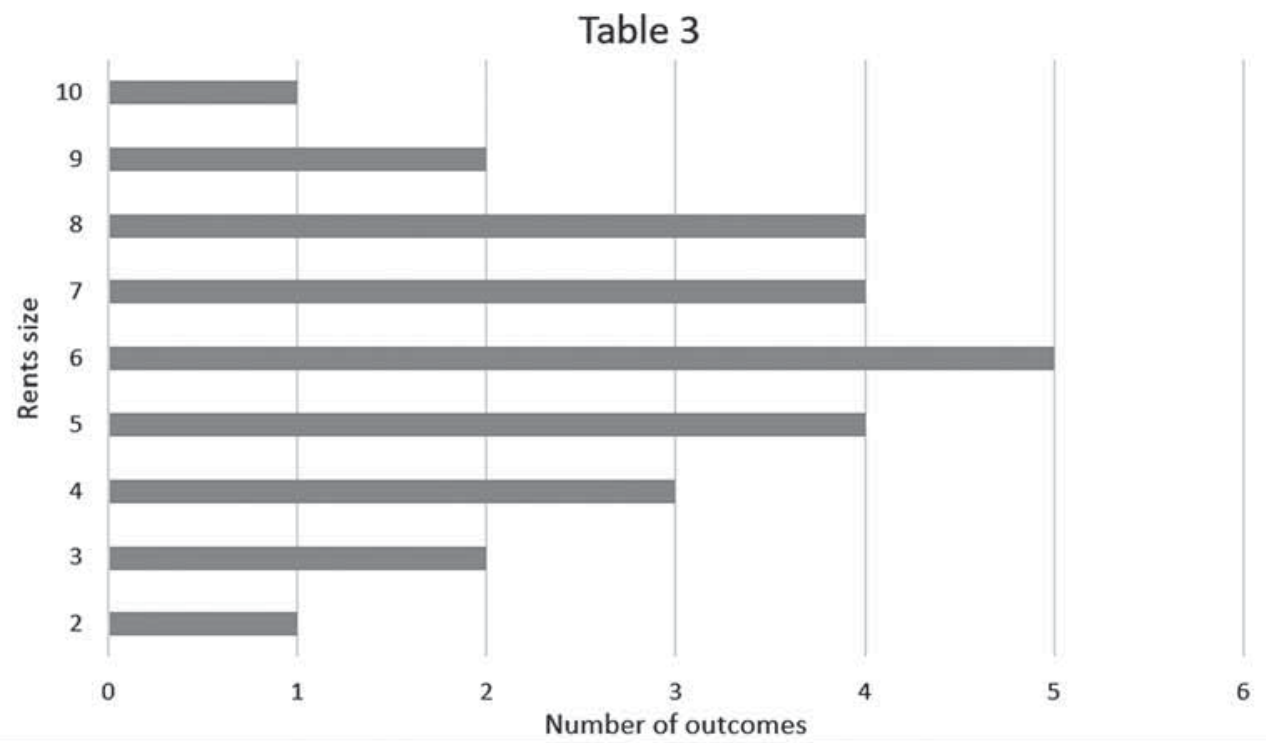


holding an office, rents are higher, but it is costly for citizens. Starting at the top of the table, an incumbent makes choices at every fork and collect his or her rents. Keeping rents low means just doing what voters want. With assumption that an incumbent is more motivated to choose outcome with higher rents to maximize benefits, we can predict what is likely to happen during an incumbent's term by comparing total rents (the numbers in gray squares).

At every step an incumbent is to choose between maximizing rents and being accountable and representative. Even though this model is very simplified and does not take into account many sufficient factors (such as concerns about credibility, term limits, being principle, etc.), it is quite relevant to demonstrate the case in general. Table 3 shows that ideal performance in which incumbent would get the smallest rents is not only unattractive but also least likely outcome ( 1 of 27 , that is $3,7037 \%$ ). For justice, the maximum rents outcome has the same possibility, but rationally acting incumbent would seek maximization rather than completely unattractive option. The most popular outcome is the mean between maximizing benefits and performing well. Each of the next strategies turns to be more beneficial. It means that even theoretically incumbents are not honest and fair, and they might be corrupted, take bribes, shirk, and implement their own policy instead of what was agreed.

\section{Conclusion}

To sum it up, the statement "elections = accountable and representative government" cannot be taken for granted. The analysis shows that neither voters nor politicians behave as they are supposed to be in a conventional theory of democracy.

Politicians strive to realize their own interests, which can match or not to match with interests of voters. Even assuming that voters are ideal (comply with all assumptions), the possibility of electing the ideal governor (getting lowest rents but currying mandate out exactly and accountable) is, according to simplified model, about 3\% (1 of 27 theoretical outcomes). Add to this that voters are biased, few informed, rarely judge retrospectively, and prefer not to spend their leisure time to politics. These circumstances will decrease already $3 \%$-possibility of setting accountable and representative government.

However, such conclusion is not to justify corruption, bribes and other types of politicians' negative behavior. This output is to emphasize that elections are not enough to ensure representative and accountable government. It is not to make us abandon democracy, but to intensify our research in the field of civil society, transparency and political activism. That's why there is a new challenge not only for politicians, but also for political scientists around the world.

\section{References}

1. Achen C.H., Bartels L.M. Democracy for Realists: Why Elections Do Not Produce Responsive Government. - Princeton: Princeton Studies in Political Behavior, 2017.

2. Bengtsson A., Wass H. Styles of Political Representation: What do Voters Expect? - UC Irvine: Center for the Study of Democracy, 2009. — URL: https://escholarship.org/uc/item/0sd3x8n0

3. Bovens M. Analysing and Assessing Accountability: A Conceptual Framework. - European Governance Paper, 2007.

4. Grofman B., Owen G., Feld S.L. Thirteen Theorems in Search of the Truth // Theory and Decision. - 1983. - Vol. 15. - P. 261-278.

5. Pitkin H.F. The Concept of Representation. — London: U of California, 1972.

6. Przeworski A., Stokes S.C., Manin B. Democracy, Accountability, and Representation. - Cambridge: Cambridge UP, 1999.

7. Schumpeter J. A. Capitalism, Socialism, and Democracy. — New York: Routledge, 1994. 